\title{
Numerical analysis of laser- welded flange pipe joints in lap and fillet configurations
}

\author{
Hubert Danielewski \\ hdanielewski@tu.kielce.pl | (D) https://orcid.org/0000-0003-4675-6236 \\ Andrzej Skrzypczyk \\ tmaask@tu.kielce.pl | (1D) https://orcid.org/0000-0003-1105-1471

\section{Wtodzimierz Zowczak} \\ wzowczak@tu.kielce.pl | (D) https://orcid.org/0000-0002-1281-9887 \\ Dariusz Gontarski \\ gontar@tu.kielce.pl | (D) https://orcid.org/0000-0002-4454-4785 \\ Leszek Ptonecki \\ plonecki@tu.kielce.pl | (iD https://orcid.org/0000-0002-7219-8568

\section{Hubert Wiśniewski} \\ hubert.w@tu.kielce.pl | (D) https://orcid.org/0000-0003-2043-1548 \\ Dominika Soboń \\ dsobon@tu.kielce.pl | (D) https://orcid.org/0000-0001-7697-6884 \\ Artur Kalinowski \\ akalinowski@tu.kielce.pl | (D) https://orcid.org/0000-0002-2720-3858

\section{Gabriel Bracha} \\ gbracha@tu.kielce.pl | (D) https://orcid.org/0000-0003-4391-864X

\section{Krzysztof Borkowski} \\ kborkowski@tu.kielce.pl | (iD https://orcid.org/0000-0003-2869-5425 \\ Kielce University of Technology; Faculty of Mechatronics and Mechanical \\ Engineering
}

Scientific Editor: Jacek Pietraszek, Cracow University of Technology

Technical Editor: Aleksandra Urzędowska, Cracow University of Technology Press Language Verification: Timothy Churcher, Merlin Language Services

Typesetting: Anna Basista, Cracow

University of Technology Press

Received: December 12, 2021

Accepted: December 29, 2021

Copyright: @ 2021 Danielewski, Skrzypczyk, Zowczak, Gontarski, Ptonecki, Wiśniewski, Soboń, Kalinowski, Bracha, Borkowski.

This is an open access article distributed under the terms of the Creative Commons Attribution License, which permits unrestricted use, distribution, and reproduction in any medium, provided the original author and source are credited. Founding: Research carried out in the NCBiR project nr LIDER/31/0173/L-8/16/ NCBR/2017 “Technology of manufacturing sealed weld joints for gas installation by using concentrated energy source".

\section{Data Availability Statement: All relevant} data are within the paper and its Supporting Information files.

Competing interests: The authors have declared that no competing interests exist. Citation: Danielewski, H., Skrzypczyk, A., Zowczak, W., Gontarski, D., Ptonecki, L., Wiśniewski, H., Soboń, D., Kalinowski, A., Bracha, G., Borkowski, K. (2021). Numerical analysis of laser-welded flange pipe joints in lap and fillet configurations. Technical Transactions: e2021030. https://doi. org/10.37705/TechTrans/e2021030

\begin{abstract}
This article presents a numerical analysis of laser-welded flange pipe joints. The presented results concern the welding of low carbon S235JR and stainless $316 \mathrm{~L}$ steels using a $\mathrm{CO}_{2}$ laser in lap and fillet joint configurations. The estimation of welding parameters was achieved using Simufact Welding software and numerical simulation, where output power, feed rate, efficiency and intensity distribution (Gaussian parameter) were analysed. In accordance with the established model, a thermo-mechanical simulation was performed. The calculated joint geometries show good agreement with experiments; therefore, the obtained results were used to study selected joint properties of both joint types. Stress-strain distribution was estimated on the basis of thermomechanical analysis. Weld bead geometry obtained from numerical simulation was compared with the results from trial joints. The numerical model established for both joint configurations shows good agreement with experimental results and were assumed to be accurate. The results of the performed analysis shown some advantages of the use of this configuration of lap joints in flange pipe joints.
\end{abstract}

Keywords: laser welding, numerical simulation, flange pipe joint, circumferential laser welding, stress-strain analysis 


\section{Introduction}

The process of laser beam welding (LBW) can be use for deep material penetration via the keyhole effect. High energy density enables the performing of welding through more than one material without the requirement for a plug weld. High velocity of laser welding combine with high energy density affect in relative low temperature accumulation, therefore, stress concentration and material deformation are lower than in classical arc welding methods. Parameters of welding processes that include LBW often are selected using experimental procedures, nevertheless this method requires many welding trials and some knowledge of the principals of laser welding (Kik, 2019). These parameters can also be estimated using analytical or numerical methods. Analytical methods provide fast results, although paying due consideration to flange pipe joints is problematic and numerical methods are required. An important challenge during numerical simulation is to determine the relevant geometry of heat sources (HS). Realistic results can be obtained using the finite elements method (FEM) and an accurate model (Kogo, 2018). Simufact Welding software are dedicated for simulation of welding applications. However Simufact use some simplification, where heat transfer are limited to conduction of solid material. The Marc solver includes the calculation of convection and other phenomena but not always directly (Piekarska 2011). Material selected for welding is low carbon structural steel of grade S235JR and stainless steel of grade 316L. Used steels are characterized as a good weldable, however differences in thermo physical properties and materials microstructure affect in some difficulties in welding. The welding of flange pipe joints due to joint configuration is problematic for classic welding methods and requires fillet joint. However, using deep material penetration via the keyhole effect, a lap welding method can be used. The stress-strain concentration can lead to cracks, that why by controlling state of stress for example by maximum principal stress those potential defects can be eliminated (Andersson, 2017). Moreover, different joint types give different properties, therefore, a comparative study of these properties is presented in this paper.

\section{Numerical simulation of the laser welding of flange pipe joints}

The numerical simulation of laser welding uses volumetric heat sources (HS), where conical sources are usually used to simulate the keyhole effect and a disc heat source is used to simulate the interaction of the laser with the material surface. Calculations using the Simufact Welding program are performed based on Fourier's law, which considers three-dimensional heat conduction (Danielewski, 2019).

The programmed simulation used both aforementioned HS, where the Gaussian parameters and the efficiency of both sources are programmed (Dziopa, 2020). The dimensions of volumetric heat sources were adopted from a separate study, where the upper radius of the conical HS is $0.4 \mathrm{~mm}$, the lower radius is $0.15 \mathrm{~mm}$ and the height of HS is $7 \mathrm{~mm}$. The disc HS has a radius of $0.45 \mathrm{~mm}$ and a depth of $0.01 \mathrm{~mm}$. The nominal size of the finite element is equal to $0.25 \mathrm{~mm}$ and $0.125 \mathrm{~mm}$ in area hear welding trajectory .

The performed simulation is based on a thermo-mechanical solution, where fusion zone geometry and maximum principal stresses were calculated. In boundary conditions, rigid restraints for welded elements are used (Dal, 2016). A disc-shaped sheet plate with a thickness of $4 \mathrm{~mm}$ of grade S235JR and with a cylindrical-shaped pipe of grade 316L were meshed using "ringmesh" with hexahedral finite elements. Weld trajectories along contact lines were determined. Simulations of welding were conducted for S235JR and 316L steels and a materials library with parameters dependent on temperature (calculated 
Fig. 1. Heat expansion in laser-welded fillet joint closing

Fig. 2. Simulated results of fusion zone geometry of: a) fillet joint, b) lap joint using JMatPro software) was used (Phanikumar, 2011). Numerical simulation for both analysed joint were performed (Fig. 1). Simulation consider time of heat source movement and cooling time, equal to $30 \mathrm{~s}$.

Welding simulations were conducted in order to estimate process parameters for complete penetration in fillet joints and melting $2 \mathrm{~mm}$ into bottom material in lap joints. For the aforementioned simulation, a constant speed rate of $1 \mathrm{~m} / \mathrm{min}$ was programmed. HS efficiency was adopted as 0.65 with Gaussian parameters of disc HS equal to 1.0 and 2.8 for conical HS. The laser output power required for full penetration in the fillet joint was $6 \mathrm{~kW}$; therefore, the same parameters as those used for lap welding were chosen (Fig. 2) (Evdokimov, 2017).

The welding of circumferential flange pipe joints is problematic due to the forced position of welding head orientation which results in limitations and some discrepancy for both methods. The results of numerical simulation provided realistic results of the welding process with a convex weld face (Ozkat, 2017). Significant differences in the welds built for fillet joints and lap joints was observed.
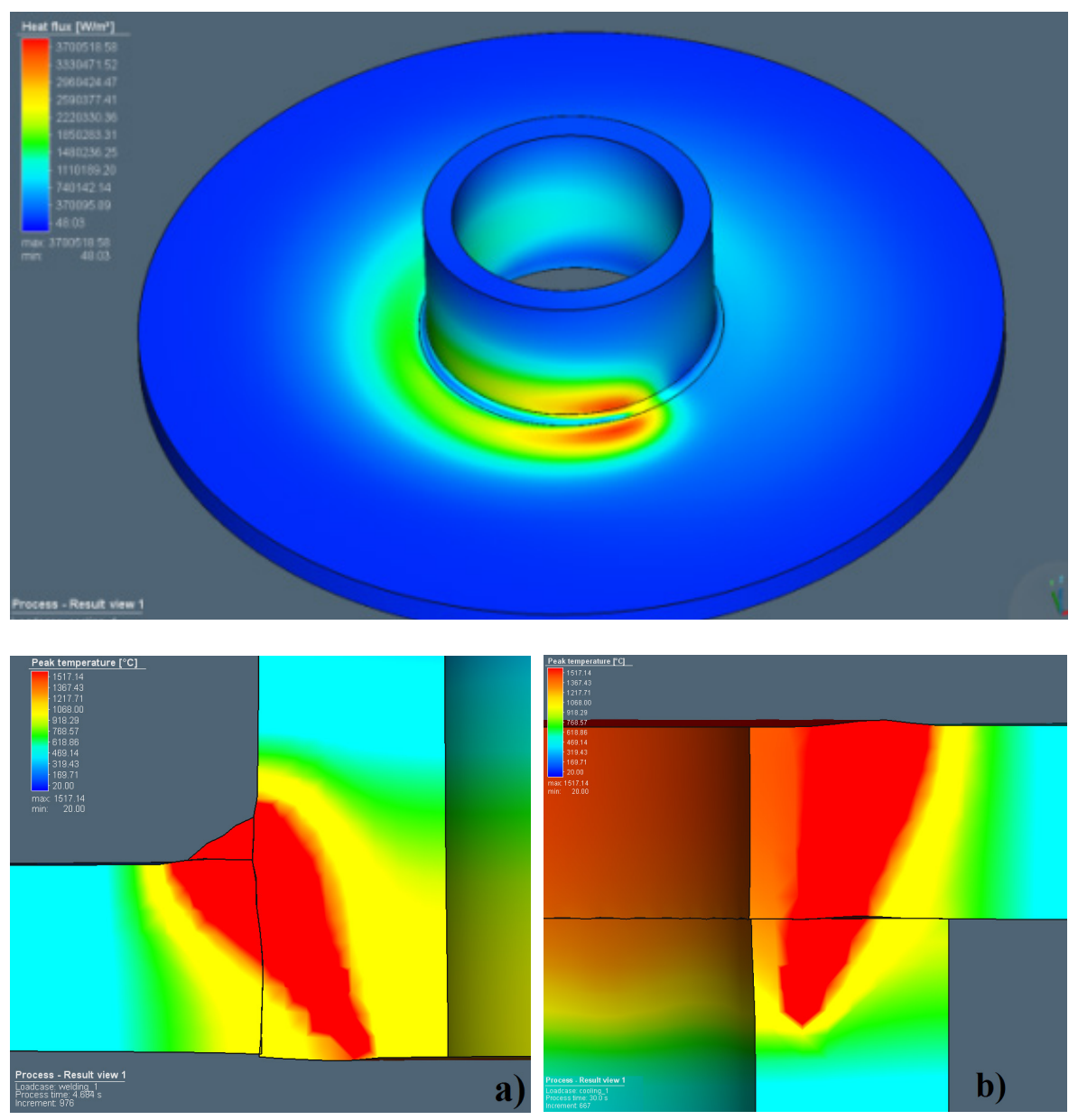

\section{Laser welding of trial joints}

The process parameters of the considered types of joints were estimated via the performed numerical simulation. The trial joints of laser welding was performed by a Trumpf TruFlow $6000 \mathrm{CO}_{2}$ laser mounted on TruLaserCell 1005 work centre. For complete joint penetration in fillet joints, output power is equal to $6 \mathrm{~kW}$ and a speed of $1 \mathrm{~m} / \mathrm{min}$ was adopted according to simulation results. Similar parameters were used for lap joint configuration. Trial welding was performed using a welding head with a focal length of $270 \mathrm{~mm}$. In order to reduce the 
plasma effect, helium with a coaxial flow rate of $15 \mathrm{l} / \mathrm{min}$ was used as a shielding gas (Fig. 3) (Radek, 2018).

A circumferential flange pipe joint using a laser welding process was obtained (Fig. 6). Complete penetration was achieved, nevertheless through the forced position of welding process head, not all joining edge was melted (region I). The obtained joints have a typical build for low carbon steel, where HAZ and BM welds can be identified (Węglowski, 2017).

The native ferritic-pearlitic structure of low carbon steel and the austenitic structure of stainless steel during the welding process lead to the creation of new material in the fusion zone, which is a combination of BMs. The metallographic study revealed a complex structure affected by phase transformation during crystallisation.

The properties of the material is related to its microstructures. Basic strength parameters can be obtained using destructive tests; however, considering the study of the flange pipe joint presented in this study, a mechanical tests are problematic. Therefore, a numerical simulation based on a thermo-mechanical solution gives the possibility to estimate some joint parameters.

Phase transformation of welded material and heat expansion generated thermal stress, which can be reduced by additional heat treatment; however, any additional heat treatment extended welding time. The maximum principal stress existing in the joint zone determine joint strength, and if stress exceeds the maximum acceptable value, it can lead to structure failure. In some cases, an additional heat treatment for stress limitation can be recommended (Derakhshan, 2018).
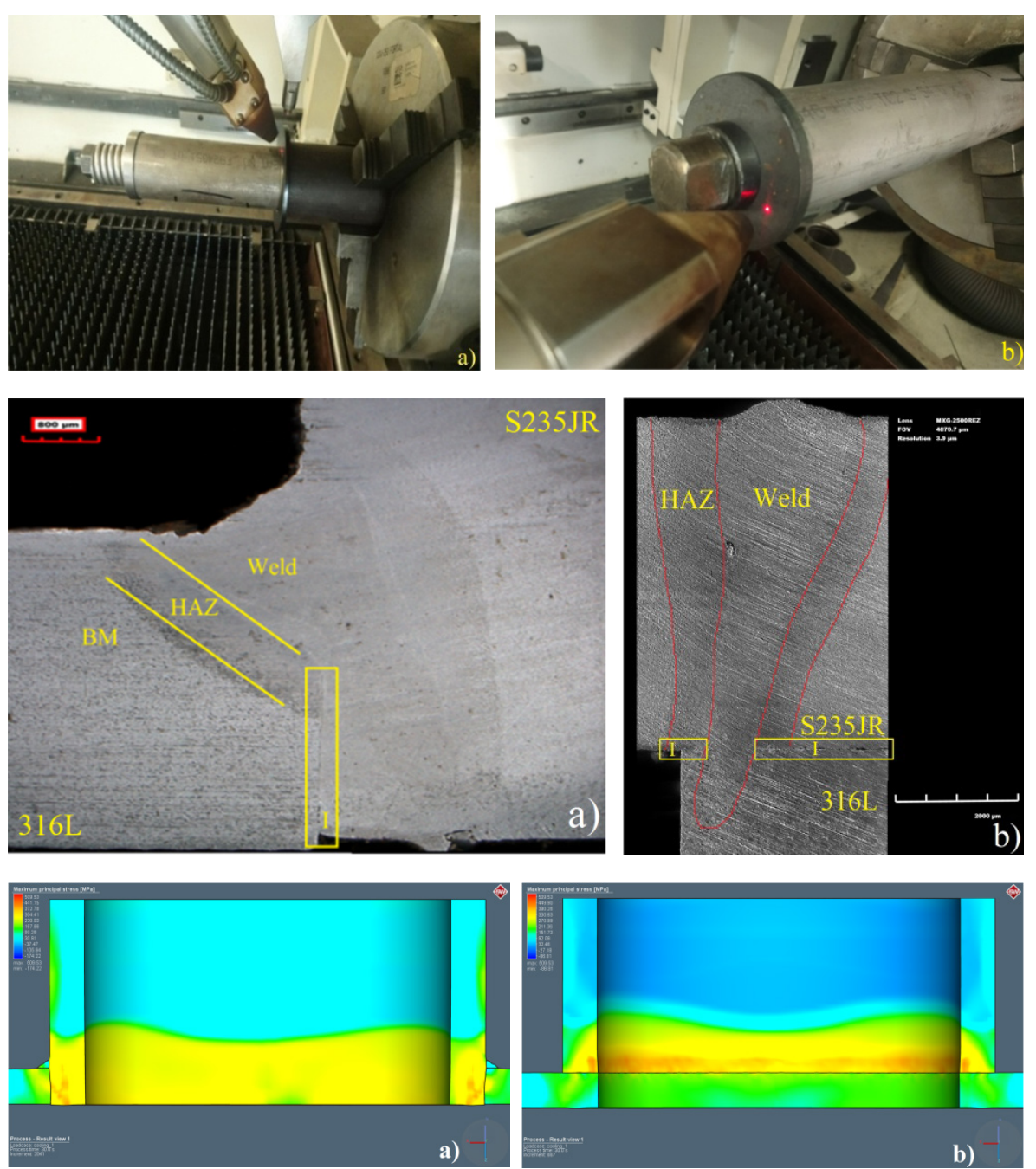

Fig. 3. Trial laser welding of flange pipe joint: a) fillet joint, b) lap joint

Fig. 4. Trial laser welding of flange pipe joint: a) fillet joint, b) lap joint configurations

Fig. 5. Maximum principal stress distribution in: a)fillet joint, b) lap joint 
Fig. 6. Total displacement of welded elements in: a) fillet joint, b) lap joint
Differences in maximum stress concentrations are significant, the highest values occur in the root of the weld in both analysed cases. In the lap joint, they occur along the contact line of the welded elements. Wider zones of maximum principal stress are observed in the fillet joint. The maximum calculated values are similar for both joint configurations. The values of stress calculated in numerical simulation do not exceed $510 \mathrm{MPa}$ in fillet joints and $450 \mathrm{MPa}$ in lap joints, where the highest concentration occurs in the weld region. Stress values in $\mathrm{HAZ}$ are elevated with respect to $\mathrm{BM}$, and the values calculated in the base material are relatively low. Due to high energy density in the LBW, heat accumulation compare to conventional welding methods is low, therefore stress-strain value are lower (Radek, 2020). The stress states in the welded joint need to be controlled; however, the obtained results shows that no additional heat treatment is required.

The welding configuration affect the welded elements displacement; therefore, this case study was analysed in cross section for both configurations (Fig. 6).

The highest values of total displacement are similar for both configurations, and occur in the fusion zone. In the lap configuration, greater displacement occurs in the plate, however welds over two materials provides sealed joint. In fillet joint greater displacement value occur between both materials and can affect in bending phenomenon.
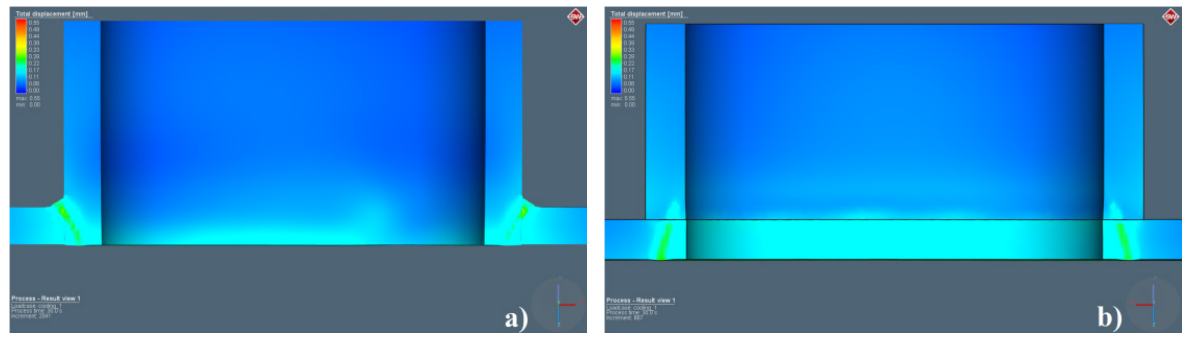

\section{Summary}

Numerical simulations of laser flange pipe joint welding were performed for two joint configurations. Thermo-mechanical analysis was used to estimate the process parameters and determine selected properties of fillet and lap joints. Using an estimated value of output power equal to $6 \mathrm{~kW}$ and a welding speed $1 \mathrm{~m} / \mathrm{min}$, trial joints were performed. The obtained simulation and experimental trial welding results showed good agreement. However, due to the welding forced position and width of fusion zones, no full penetration of welded materials was obtained. Stress analysis based on numerical simulation showed low stress concentration. Some stress value were identified only in weld and HAZ in both configurations. Higher values of maximum principal stress occur in fillet joints. Moreover, total displacements of welded elements are less favourable in this joint configuration. The presented study has shown an alternative possibility for flange pipe joint welding, where properties in lap joint relative to fillet joint welded with the same process parameters show some advantages. Depending upon weld requirements, lap joints can be used for performing flange pipe joints as an alternative joint configuration.

\section{References}

Kik, T., Górka, J. (2019). Numerical Simulations of Laser and Hybrid S700MC T-Joint Welding. Materials (Basel), 12 (516), https://doi.org/10.3390/ ma12030516

Kogo, B., Wang, B., Wrobel, L.,Chizari, M. (2018). Experimental and Numerical Simulation of Girth Welded Joints of Dissimilar Metals in Clad Pipes. 
International Journal of Offshore and Polar Engineering, 28, 380-386, https://doi.org/10.17736/ijope.2018.oa22

Piekarska, W., Kubiak, M., Bokota, A. (2011). Numerical simulation of thermal phenomena and phase transformations in laser-arc hybrid welded joints. Archives of Metallurgy and Materials, 56, 409-421, DOI:10.2478/v10172011-0044-6

Andersson, O., Budak, N., Melander, A., Palmquist, N. (2017). Experimental measurements and numerical simulations of distortions of overlap laserwelded thin sheet steel beam structures. Welding in the World, 61, 927-934, DOI: 10.1007/s40194-017-0496-z

Danielewski, H. (2019). Laser welding of pipe stubs made from super 304 steel. Numerical simulation and weld properties. Technical Transactions, 116(1), 167-176, DOI:10.4467/2353737XCT.19.011.10051

Dziopa, I., Pata, T. (2020). Influence of LWE on Strength of Welded Joints of HSS S960-Experimental and Numerical Analysis. Materials, 13, 1-19, https:// doi.org/10.3390/ma13030747

Dal, M., Fabbro, R. (2016). An overview of the state of art in laser welding simulation. Optics \& Laser Technology, 78, 2-14, DOI:10.1016/j. optlastec.2015.09.015

Phanikumar, G., Chattopadhyay, K., Dutta, P. (2011). Joining of dissimilar metals: issues and modelling techniques. Science and Technology of Welding and Joining, 16, 313-317, https://doi.org/10.1179/136217181 $1 Y .0000000014$

Evdokimov, A., Springer, K., et al. (2017). Heat source model for laser beam welding of steel-aluminum lap joints. The International Journal of Advanced Manufacturing Technology, 93, 709-716, https://doi.org/10.1007/s00170017-0569-6

Ozkat, E., Ceglarek, D., et. all. (2017). Development of decoupled multi-physics simulation for laser lap welding considering part-to-part gap. Journal of Laser Applications, 29, 022423, https://doi.org/10.2351/1.4983234

Radek, N., Pietraszek, J., Goroshko, A. (2018). The Impact of Laser Welding Parameters on the Mechanical Properties of the Weld. AIP Conference Proceedings, 020025, DOI:10.1063/1.5056288

Węglowski, M., Niagaj, J., et. all. (2017). Mechanical properties and metallographic characteristics of girth welded joints made by the arc welding processes on pipe steel grade API 5L X70. Advances In Manufacturing Science And Technology, 41(4), 51-62, DOI:10.2478/amst-2017-0022

Derakhshan, E., Yazdian, N., et. all. (2018). Numerical simulation and experimental validation of residual stress and welding distortion induced by laser-based welding processes of thin structural steel plates in butt joint configuration. Optics \& Laser Technology, 104, 170-182, https://doi. org/10.1016/j.optlastec.2018.02.026

Radek, N., Pietraszek, J., Gądek-Moszczak, A., et all. (2020). The Morphology and Mechanical Properties of ESD Coatings before and after Laser Beam Machining. Materials, 13, 2331, https://doi.org/10.3390/ma13102331 